\title{
Coordination Strategy for a New Retail Supply Chain Based on Combination Contract
}

\author{
Shuiwang Zhang $\left(\mathbb{D}\right.$, Yu Mei $\mathbb{D}^{D}$, Qiang Bao $\mathbb{D}^{D}$, and Lingzhi Shao \\ School of Management Science and Engineering, Anhui University of Technology, Ma'anshan 243032, China \\ Correspondence should be addressed to Shuiwang Zhang; zsw0022@ahut.edu.cn
}

Received 27 July 2020; Revised 9 January 2021; Accepted 2 February 2021; Published 15 February 2021

Academic Editor: Toshikazu Kuniya

Copyright (C) 2021 Shuiwang Zhang et al. This is an open access article distributed under the Creative Commons Attribution License, which permits unrestricted use, distribution, and reproduction in any medium, provided the original work is properly cited.

\begin{abstract}
The supply chain in the new retail context demands higher requirements on the price, service, and logistics level. It is very important to seek the coordination among the optimal price, service level, and logistics level. In this paper, we propose the coordination of pricing, the service level, and delivery time of a new retail supply chain composed of one product supplier, one platform service provider, and one logistics provider. Firstly, the profit function mode of product pricing, platform service level, and logistics distribution level that influence the consumers' demand is constructed in two modes, namely, the centralized and decentralized decision mode. Then, we calculate and compare the optimal product price, the optimal platform service level, the optimal delivery time, and the profit of each member of the supply chain from both decision modes. We discovered that cooperation improves the service level, logistics level, and the income of each member of the new retail supply chain. Therefore, we propose a novel mode called the coordination mode as a strategy for the supply chain based on the combination contract. We performed a numerical analysis to demonstrate the feasibility and effectiveness of the coordination contract.
\end{abstract}

\section{Introduction}

Since 2015, the physical retail enterprises have been developing online markets, while the traditional e-commerce enterprises have been expanding in the offline channels. The retail giant Walmart has acquired five e-commerce enterprises, including Jet.com and ShoeBuy, since August 2016 to establish its online retail layout. In November 2015, Amazon opened its first physical bookstore in Seattle, and since July 2015, Alibaba has been cooperating with Unilever, Bailian Group, and other companies to increase its online and offline sales and to explore new retail modes based on the logistics and warehousing advantages of offline physical stores. JD has also cooperated with Yonghui supermarket, Walmart, and others to obtain additional profits by combining offline retail giants and online consumers. Apparently, the retail business will continue to expand, and it will break the current market boundaries and realize its integration of online market, offline market, and logistics. Jack Ma coined the term "new retail" to describe this phenomenon at the cloud conference of Alibaba in October 2016. He pointed out that there will be no e-commerce in the future and that offline and online marketing should be combined with logistics to create an effective method, called new retail.

The formal standard for the concept of new retail is not developed yet. Generally, the new retail concept has these properties: it is consumer-oriented, based on modern technology, strongly integrating online, offline, and logistics, and providing consumers with comprehensive services. The new retail supply chain is mainly composed of product suppliers, platform service providers, and logistics providers. Product suppliers are the starting point of the supply chain who are responsible for providing the products. Logistics providers are responsible for product storage, distribution, and some other logistics services. Logistics improvement shall be reflected in the reduction of consumers' waiting time, which leads to the consumers' satisfaction improvement for both online and offline retails. Some online platforms (e.g., Amazon.cn and JD.com) have a huge investment 
in creating their own logistics systems to deliver the products. Compared with these high-cost private logistics systems, some platform service providers (e.g., Tmall.com) opted to outsource the logistics services to the third-party logistics service providers and carefully considered the risk of poor service.

As the online transaction business develops, online platforms gradually evolved from single information platforms to comprehensive transaction platforms that include a market promotion, brand building, online payment, logistics information, after-sales service, dispute settlement, and so on. Some product suppliers and platform service providers are integrated, such as JINGDONG Mall and Suning e-shopping, in which the platform service providers not only serve as a third-party trading platform for the product suppliers but also conduct their own business. On the contrary, some product suppliers and platform service providers might have different roles in the online trading process and they have clear task boundaries, for example, TAOBAO and Tmall.

New retail is a novel concept; however, it still holds the essence of retail, namely, to provide consumers with valueadded products and services efficiently, the basis of which is the continuous upgrade and reconstruction of the supply chain. To understand the role of each participant of the new retail supply chain, we simulated the product supplier, the platform service provider, and the logistics provider as three independent entities and assigned them on the roles of online, offline, and logistics. Specifically, we analyzed the impact of suppliers' product pricing, platform service providers' service level, and logistics providers' delivery level on the supply chain operation and searched for the most efficient cooperation solutions with the highest benefits. We hope our research shall promote new ideas and an effective coordination mechanism for retail enterprises in the new retail supply chain.

The structure of this paper is arranged in the following order. The relevant studies are analyzed in Section 2. Section 3 describes the problems of the new retail supply chain, the centralized and decentralized supply chain decision mode, and the comparison of the optimal price, service level, and delivery level decisions from each mode. In Section 4, we discuss the supply chain coordination strategy (coordination mode) based on the combination contract. Section 5 presents a numerical analysis to demonstrate the feasibility of supply chain coordination strategies. Finally, Section 6 summarizes the research findings and discusses the future research direction.

\section{Literature Review}

2.1. Online Platform of the New Retail Supply Chain. A group of research studies focused on the strategic selling mode of online platforms, such as a study by Qi et al. [1] who studied the agency selling effects on reselling in the hybrid platforms and its boundary conditions. Han et al. [2] studied the optimal pricing and the variations in profits under the manufacturer-owned and retailer-owned online channel. Gümüş et al. [3] analyzed the pricing strategies combined with handling and shipping fees to fully understand the delivery complexity in online commerce. Some literatures also studied other functions of the online platforms, such as the consumers' privacy protection [4], online payment security [5], information provision [6], after-sales services [7], and e-service quality evaluation [8]. Some researchers also studied the online channel choice problem of retailers $[9,10]$. These papers mainly study some independent functions of online platform but do not take it as an important member of the supply chain to study its impact on the whole supply chain. The paper aimed to study the impact of the online platform in the new retail supply chain. To simplify the research, various functions of the online platform are analyzed as the service level.

2.2. Logistics Service of the New Retail Supply Chain. Many researchers worked on the logistics of online transactions. Al-nawayseh et al. [11] studied an important challenging issue, that is, the last mile logistics in online grocery shopping and discovered the pickup point solution as the best logistics strategy for online grocery retailers. Koptak et al. [12] offered a standard to assess the quality and price parameters for fair 3PL (Third-Part Logistics) contract to support the suppliers and the logistics providers to establish long-term win-win relationships. Qin et al. [13] studied the logistics service sharing strategy that affects the profits of the platform and the seller. Zhao and $\mathrm{Hu}$ [14] optimized the solution of the collection and delivery points layout problem between online retailers and the customers to improve the urban end distribution level in e-commerce logistics. Peng et al. [15] investigated the strategy which an offline retailer delivers online orders from the retailer's warehouse for a dual-channel manufacture. Murfield et al. [16] investigated the logistics service quality impact on consumer satisfaction and loyalty. Some literatures studied the mode selection of e-commerce logistics and compared and analyzed the advantages and disadvantages of self-built (private) and third-party logistics $[17,18]$ while others observed the methods to improve the logistics management and service quality $[19,20]$.

2.3. Supply Chain Coordination. Generally, supply chain coordination is achieved through supply chain contracts that mainly includes quantity discount contract [21], revenue sharing contract [22], buyback contract [23], sales rebate contract [24], compensation contract [25], cost-sharing contract [26], and so on, and some complex supply chain coordination requires the joint use of two or more of these contracts $[27,28]$. Under the assumption of the new retail concept, the consumers possess higher requirements for service and time. In the previous studies, the combination of price and time creates higher competitive advantages to the supply chain [29], for instance, the coordination between lead time and pricing [30] and the coordination between service level and pricing [31]. Some literatures also explored on the cooperation relationship influence between service level and lead time [32] or pricing and inventory [33], multichannel supply chain coordination problem [34, 35], 
and the revenue cooperation relationship among distributors, platforms, and logistics providers [36].

In summary, the existing literatures performed studies from the aspects of logistics service, platform service, and optimal pricing. However, we found few literatures that consider the product price, platform service, and logistics service simultaneously. To analyze the cooperation of online, offline, and logistics under the concept of the new retail supply chain, we considered the new retail supply chain to be composed of product suppliers, platform service providers, and logistics providers, compared and analyzed the optimal pricing, service level, and delivery time decisions of each agent under centralized decision and decentralized decision mode, and established a combination contract to coordinate the cooperation among the product suppliers, the platform service providers, and the logistics providers.

\section{Problem Description and Decision Modes}

3.1. Problem Description. In this paper, the new retail supply chain mode consists of product suppliers, platform service providers, and logistics providers. The product suppliers are responsible for providing products, the platform service providers are responsible for online sales, customer online consultation, online payment, and after-sales services, and the logistics providers are responsible for product storage and distribution. The product suppliers could be the product manufacturers, the distributors, or the retailers, and they authorize the logistics providers in storing the products and the platform service providers in selling the products. When the customers successfully place an online order, the platform service providers send the order information to the logistics providers. Then, the logistics providers begin to select, deliver the products, and send the feedbacks of the delivery information to the platform service providers. After the consumers confirm the receipt, this transaction is completed, and the platform service providers send feedbacks of the transaction information to the product suppliers. The new retail supply chain operation is shown in Figure 1.

In the new retail market, customers' demand is no longer affected by the product price; instead, the platform service providers' service level and the waiting time will have strong impacts on consumers' purchase intention. Logistics providers also play an important role to improve the online transactions. Low level of logistics services, such as delivery delay or product damage, will damage the customer satisfaction and loyalty, leading to higher possibility of losing customers. Likewise, in online shopping, the service level of the online platform has a significant influence on the consumers' purchase intention, in which a higher service level certainly will bring a higher purchase rate.

In this paper, we selected the delivery time as the research target of the logistics level and summarized the various platform services of product promotion, online consultation, and after-sales service, as the service level. Certainly, to shorten the delivery time and to increase the service level are of the utmost importance. However, shorter delivery time and higher service level will lead to higher product price. Thus, the key point of this paper is the method to balance the relationship among price, platform service level, and delivery time. We discussed this matter in detail in the following section.

3.2. Demand Function. We assume that the new retail supply chain provides one product to the market, that the product suppliers have enough supply capacity to meet the market demand, and that the consumers are affected to the same extent by the product price, service level, and delivery time. According to [37], we consider the product demand in the market as a linear function of the product price, which decreases with the increasing price. As for the impact of delivery time on consumer demand, we adopt the assumption in a study by So and Song [38] that demand and time are linearly negatively correlated. The effect of platform service providers on the product suppliers is similar to the effect of retailers on manufacturers in the traditional supply chain, which the effort level of the retailers will increase the demand from the manufacturers. Based on these assumptions, we infer that the services provided by the platform service providers to the product suppliers shall increase the demand of the products from the consumers, and this increase in demand is linearly related to the service level of the platform service providers.

Hence, the consumers' demand can be represented as follows:

$$
D=a-b_{1} p-b_{2} t+b_{3} e,
$$

where $D$ denotes the consumers' demand of the product, $a$ is the consumers' basic demand of the product, $p$ is the product price, $t$ is the waiting time for the customers to receive the products after placing the order, $e$ is the service level of the platform provider, and $b_{1}, b_{2}$, and $b_{3}$ represent the price sensitivity coefficient of demand, the delivery time sensitivity coefficient of demand, and the service level sensitivity coefficient of demand, respectively.

3.3. Cost Function. The logistics cost is negatively correlated with the delivery time, that is, shorter the logistics time results in a higher increase in logistics cost and vice versa [39]. Hence, the logistics cost function can be represented as follows:

$$
d=c_{l}+\frac{\alpha}{t},
$$

where $d$ denotes the logistics cost, $c_{l}$ represents the inherent logistics cost that is independent of the delivery time, $\alpha$ is the sensitivity coefficient of logistics cost to delivery time, and $t$ is the delivery time. By referring to the quadratic form of quality cost expression in [40], the platform service cost can be represented as follows:

$$
c_{e}=\beta \frac{e^{2}}{2},
$$

where $c_{e}$ denotes the platform service cost, $\beta$ is the platform service cost coefficient, and $e$ is the platform service level. 


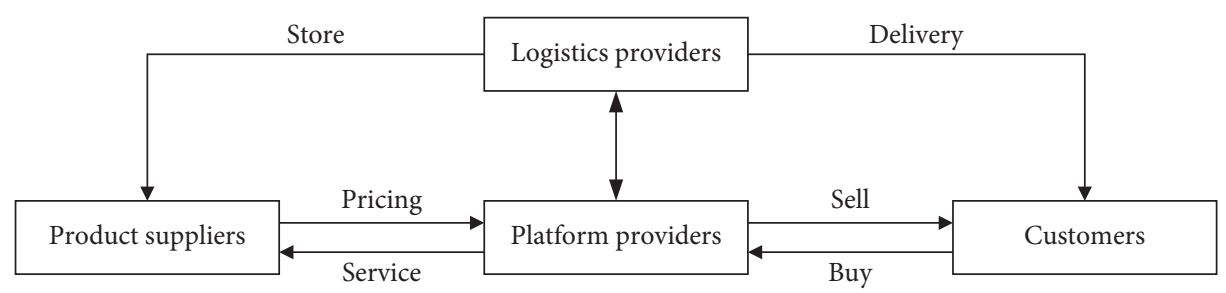

FIgURE 1: New retail supply chain operation diagram.

\section{Basic Modes}

4.1. Centralized Decision Mode Supply Chain. For a decentralized decision mode supply chain, each of the decision makers makes decisions with the goal of maximizing its own profits. However, in a centralized decision mode supply chain, it is unnecessary to consider the income of individual decision makers but to make decisions based on the overall supply chain benefit. In this paper, the profit of a single enterprise is not necessarily affected the optimal decision of product price pc, service level $e_{c}$, and delivery time $t_{c}$ based on the total profit of supply chain. The cost composition includes product cost $c$, platform service $\cos t c_{e}$, and logistics $\operatorname{cost} d_{c}$. Hence, the total profit function of the supply chain $\pi_{c}$ and the market demand function $D_{c}$ is as follows:

$$
\begin{aligned}
\pi_{c} & =\left(p_{c}-c-d_{c}\right) D_{c}-c_{e}, \\
D_{c} & =\left(a-b_{1} p_{c}-b_{2} t_{c}+b_{3} e_{c}\right),
\end{aligned}
$$

and the platform service cost function $c_{e}$ and logistics cost dc are modified from (2) and (3):

$$
\begin{aligned}
& c_{e}=\beta \frac{e_{c}^{2}}{2}, \\
& d_{c}=c_{l}+\frac{\alpha}{t_{c}},
\end{aligned}
$$

where $e_{c}$ is the platform service of the centralized decision mode and $t_{c}$ is the delivery time of the centralized decision mode.

Hence, the total profit function of the supply chain $\pi_{\mathrm{c}}$ can be expressed as follows:

$$
\pi_{c}=\left(p_{c}-c-c_{l}-\frac{\alpha}{t_{c}}\right)\left(a-b_{1} p_{c}-b_{2} t_{c}+b_{3} e_{\partial c}\right)-\beta \frac{e_{c}^{2}}{2}
$$

The optimization problem of the centralized decision mode can be expressed as follows:

$$
\begin{aligned}
\max \pi_{c}\left(p_{c}, e_{c}, t_{c}\right)= & \left(p_{c}-c-c_{l}-\frac{\alpha}{t_{c}}\right) \\
& \cdot\left(a-b_{1} p_{c}-b_{2} t_{c}+b_{3} e_{c}\right)-\beta \frac{e_{c}^{2}}{2} .
\end{aligned}
$$

Theorem 1. The optimal price, service level, and delivery time in the centralized decision mode supply chain is

$$
\left\{\begin{array}{l}
p_{c}=\frac{\left[\left(a+b_{1} c+b_{1} c_{l}\right) \beta-b_{3}^{2}\left(c+c_{l}\right)\right] \sqrt{b_{1} b_{2} \alpha}-b_{2} b_{3}^{2} \alpha}{\left(2 b_{1} \beta-b_{3}^{2}\right) \sqrt{b_{1} b_{2} \alpha}} \\
e_{c}=\frac{\left(a-b_{1} c-b_{1} c_{l}-2 \sqrt{b_{1} b_{2} \alpha}\right) b_{3}}{2 b_{1} \beta-b_{3}^{2}} \\
t_{c}=\sqrt{\frac{b_{1} \alpha}{b_{2}}}
\end{array}\right.
$$

We prove this theorem by solving the second derivative of equation (8), as detailed in the appendix.

We got the mathematical expressions of the optimal price, service level, and delivery time that can maximize the profit of the supply chain. Next, we will discuss the optimal decisions under the decentralized decision mode supply chain.

4.2. Decentralized Decision Mode Supply Chain. On the decentralized decision mode, the product suppliers, the platform service providers, and the logistics providers make independent decisions to maximize their own profits. The product suppliers decide the product price, the platform service providers decide the optimal service level and the service cost, and the logistics providers decide the optimal logistics price and the delivery time. Successful product sales from the product suppliers cannot be achieved without professional services provided by the platform service providers and the logistics providers. Therefore, in this paper, we assumed that the product suppliers pay both platform service fee and logistics delivery fee.

The decision process is as follows. We assumed that both the platform service providers and the logistics providers charge the product suppliers according to the volume of the product transactions, specifically, the platform service providers charge $m_{p}$ for unit product and the logistics providers charges $m_{l}$ for unit product from the product suppliers. Then, we assumed that the logistics providers decide the unit product logistics cost and delivery time first, followed by the platform service providers to decide the service level and unit product service cost, and finally, the product suppliers decide the product price by considering the decisions of logistics providers and the platform service providers besides with their own cost and target profit.

By using the reverse solution method, we solve the optimal decision of the product suppliers with known logistics price $m_{2}$, delivery time $t_{d}$, service level $e_{d}$, and service price $m_{1}$. Hence, the profit function of the product suppliers $\pi_{s d}$ can be expressed as follows: 


$$
\pi_{s d}=\left(p_{d}-c-m_{p}-m_{l}\right)\left(a-b_{1} p_{d}-b_{2} t_{d}+b_{3} e_{d}\right),
$$

where $p_{d}$ is the product price of the decentralized decision mode, $c$ is the product cost, $a$ is the consumers' basic demand of the product, $b_{1}$ is the price sensitivity coefficient of demand, $b_{2}$ is the delivery time sensitivity coefficient of demand, and $b_{3}$ is the service level sensitivity coefficient of demand.

Theorem 2. . The optimal price, service level, and delivery time in the centralized decision mode supply chain is

$$
\left\{\begin{array}{l}
p_{d}=\frac{\left(a-b_{2} t_{d}+b_{3} e_{d}\right)+b_{1}\left(c+m_{p}+m_{l}\right)}{2 b_{1}} \\
e_{d}=\frac{b_{3} m_{p}}{2 \beta} \\
t_{d}=\sqrt{\frac{b_{1} \alpha}{b_{2}}}
\end{array}\right.
$$

We also obtain the optimal platform service level equation $e_{d}$ by solving the first and second partial derivative, and we put the detailed solution procedure in the appendix:

$$
e_{d}=\frac{b_{3} m_{p}}{2 \beta}
$$

By integrating $p_{d}$ and $e_{d}$, we get the following:

$$
\pi_{p d}\left(m_{p}\right)=-\left(b_{1}+\frac{b_{3}^{2}}{2 \beta}\right) m_{p}^{2}+\frac{a-b_{2} t_{d}+b_{3} e_{d}-b_{1}\left(c+m_{l}\right)}{2} m_{p} .
$$

The first partial derivative and the second partial derivative of $m_{1}$ are as follows:

$$
\begin{aligned}
& \frac{\partial \pi_{p d}}{\partial m_{p}}=-2\left(b_{1}+\frac{b_{3}^{2}}{8 \beta}\right) m_{p}^{2}+\frac{a-b_{2} t_{d}+b_{3} e_{d}-b_{1}\left(c+m_{l}\right)}{2} \\
& \frac{\partial^{2} \pi_{p d}}{\partial m_{p}^{2}}=-2\left(b_{1}+\frac{b_{3}^{2}}{8 \beta}\right) m_{p}^{2}<0 .
\end{aligned}
$$

Likewise, the optimal platform service price is as follows:

$$
m_{p}=\frac{2 \beta\left[a-b_{2} t_{d}-b_{1}\left(c+m_{l}\right)\right]}{4 b_{1} \beta-b_{3}^{2}} .
$$

Then, for the logistics providers, their profit function can be expressed as follows:

$$
\pi_{l d}=\left(m_{l}-c_{l}-\frac{\alpha}{t_{d}}\right)\left(a-b_{1} p_{d}-b_{2} t_{d}+b_{3} e_{d}\right)
$$

By assuming that the delivery time is a fixed value, the optimal logistics price $m_{l}$ can be obtained by the following:

$$
m_{l}=\frac{-2 b_{1}^{2} c_{e} \beta+4 c_{l} b_{1}^{2} \beta+b_{1} c_{l} b_{3}^{2}+2 a b_{1} \beta+2 b_{1} \beta \sqrt{b_{2} b_{1} \alpha}+b_{3}^{2} \sqrt{b_{1} b_{2} \alpha}}{b_{1}\left(6 b_{1} \beta+b_{3}^{2}\right)}
$$

and the optimal delivery time is as follows:

$$
t_{d}=\sqrt{\frac{b_{1} \alpha}{b_{2}}}
$$

By integrating $p_{d}, e_{d}, m_{1}, m_{2}, D_{d}$, and $\pi_{d}$, we obtained the market demand mathematical expression and the supply chain total profit mathematical expression under the decentralized decision mode as follows:

$$
\begin{aligned}
D_{d}= & a-\frac{b_{1}\left[\left(a-b_{2} t_{d}+b_{3} e_{d}\right)+b_{1}\left(c+m_{p}+m_{l}\right)\right]}{2 b_{1}} \\
& -\sqrt{b_{1} b_{2} \alpha}+b_{3} \frac{b_{3} m_{p}}{2 \beta} \\
\pi_{d}= & \pi_{s d}+\pi_{p d}+\pi_{l d}=\left(a-b_{1} p_{d} t_{d}+b_{3} e_{d}\right) \\
& \left(p_{d}-c-c_{1}-\frac{\alpha}{t_{d}}\right)-\beta \frac{e_{d}^{2}}{2} .
\end{aligned}
$$

We presented the calculation results of the centralized and decentralized decision modes in Table 1 . In this table, $p$ means product price, $e$ means platform service level, $t$ means delivery time, $D$ means market demand, and $\pi$ means supply chain profit.

4.3. Comparative Analysis of the Centralized and Decentralized Decision Modes. We derived four propositions to compare the product price, platform service level, delivery time, and supply chain profit of the centralized decision mode and the decentralized decision mode.

Proposition 1. The centralized decision mode has a better optimal platform service level compared with the decentralized decision mode $\left(e_{c}>e_{d}\right)$.

Proof.

$$
\begin{gathered}
e_{d}=\frac{b_{3}\left[a-\sqrt{b_{1} b_{2} \alpha}-b_{1}\left(c+m_{l}\right)\right]}{4 b_{1} \beta-b_{3}^{2}}<\frac{b_{3}\left[a-\sqrt{b_{1} b_{2} \alpha}-b_{1}\left(c+m_{l}\right)\right]}{2 b_{1} \beta-b_{3}^{2}}=e_{d}^{*}, \\
e_{d}^{*}-e_{c}=\frac{b_{3}\left[\sqrt{b_{1} b_{2} \alpha}-b_{1} m_{l}+b_{1} c_{l}\right]}{2 b_{1} \beta-b_{3}^{2}}=\frac{b_{3}\left[4 b_{1} \beta \sqrt{b_{1} b_{2} \alpha}+2 c_{l} b_{1}^{2} \beta+2 b_{1}^{2} c \beta-2 a b_{1} \beta\right]}{2 b_{1} \beta-b_{3}^{2}} .
\end{gathered}
$$


TABLE 1: Centralized and decentralized decision mode calculation results.

\begin{tabular}{lcc}
\hline Parameter & Centralized decision mode & Decentralized decision mode \\
\hline$p$ & $p_{c}=\left(\left(\left(a-b_{2} t_{c}+b_{3} e_{c}\right)+b_{1}\left(c+c_{l}+\left(\alpha / t_{c}\right)\right)\right) /\left(2 b_{1}\right)\right)$ & $p_{d}=\left(\left(\left(a-b_{2} t_{d}+b_{3} e_{d}\right)+b_{1}\left(c+m_{p}+m_{l}\right)\right) /\left(2 b_{1}\right)\right)$ \\
$e$ & $e_{c}=\left(\left(\left(a-b_{1} c-b_{1} c_{l}-2 \sqrt{b_{1} b_{2} \alpha}\right) b_{3}\right) /\left(2 b_{1} \beta-b_{3}^{2}\right)\right)$ & $e_{d}=\left(\left(b_{3}\left[a-\sqrt{b_{1} b_{2} \alpha}-b_{1}\left(c+m_{l}\right)\right]\right) /\left(4 b_{1} \beta-b_{3}^{2}\right)\right)$ \\
$t$ & $t_{c}=\sqrt{\left(\left(b_{1} \alpha\right) / b_{2}\right)}$ & $t_{d}=\sqrt{\left(\left(b_{1} \alpha\right) / b_{2}\right)}$ \\
$D$ & $D_{c}=a-b_{1} p_{c}-b_{2}+b_{3} e_{c}$ & $D_{d}=a-b_{1} p_{d}-b_{2} t_{d d}+b_{3} e_{d}$ \\
$\pi$ & $\pi_{c}=\left(p_{c}-c-c_{l}-\left(\alpha / t_{c}\right)\right) D_{c}-\beta\left(e_{c}^{2} / 2\right)$ & $\pi_{d}=\left(p_{d}-c-c_{l}-\left(\alpha / t_{d}\right)\right) D_{d}-\beta\left(e_{d}^{2} / 2\right)$ \\
\hline
\end{tabular}

Since $\quad b_{3}>0 \quad$ and $2 b_{1} \beta-b_{3}^{2}>0$, then $2 b_{1} \beta \sqrt{b_{1} b_{2} \alpha}+c_{l} b_{l}^{2} \beta+b_{1}^{2} c \beta-a b_{1} \beta<0$; thus, $e_{d}<e_{d}^{*}<e_{c}$, leading to $e_{c}>e_{d}$.

It indicates that compared with the decentralized decision supply chain mode, the centralized decision mode has a high optimal platform service level. The new retail supply chain wants to gain enough profits through online channels, and it is crucial to improve the service level of the platform. The supply chain with the centralized decision mode can better mobilize resources to improve the service level of the platform. Therefore, new retail enterprises should strengthen cooperation.

Proposition 2. The centralized decision mode has the same optimal delivery time with the decentralized decision mode $\left(t_{c}=t_{d}\right)$.

Proof. From equations (9) and (18), we get the following:

$$
t_{c}=\sqrt{\frac{b_{1} \alpha}{b_{2}}}=t_{d}=\sqrt{\frac{b_{1} \alpha}{b_{2}}} .
$$

It shows that the optimal delivery time curve is equivalent, indicating that the optimal delivery time is equal for both decision modes, because the optimal delivery time is determined by the level of social productivity and logistics cost, and it is not affected by the operation modes of the supply chain. However, shortening the delivery time helps the supply chain to win more satisfaction of customer, so new supply chain enterprises should increase the investment in logistics construction to shorter delivery time.

Proposition 3. The centralized decision mode has a lower optimal product price compared with the decentralized decision mode $\left(p_{c}<p_{d}\right)$.

Proof. From equations (9) and (11), we get the following:

$$
\begin{gathered}
p_{c}=\frac{\left(a-b_{2} t_{c}+b_{3} e_{c}\right)+b_{1}\left(c+c_{l}+\left(\alpha / t_{c}\right)\right)}{2 b_{1}}, \\
p_{d}-p_{c}=\frac{b_{3}}{2 b_{1}}\left(e_{d}-e_{c}\right)+\frac{\left(m_{p}+m_{l}\right)-\left(c_{l}+\left(\alpha / t_{c}\right)\right)}{2 b_{1}},
\end{gathered}
$$

when $\quad a b_{1} \beta^{2}-b_{l}^{2} c \beta^{2}-2 b_{1} \beta^{2} \sqrt{b_{1} b_{2} \alpha}-b_{1}^{2} c_{1} \beta^{2}>0, p_{c}<p_{d}$, and

$$
\begin{aligned}
& \frac{\left(m_{l}+m_{p}\right)-\left(c_{l}+\left(\alpha / t_{c}\right)\right)}{2 b_{1}} \\
& =\frac{8 a b_{1} \beta^{2}-8 b_{1}^{2} c \beta^{2}-16 b_{1} \beta^{2} \sqrt{b_{1} b_{2} \alpha}-8 b_{1}^{2} c_{l} \beta^{2}}{\left(6 b_{1} \beta+b_{3}^{2}\right)\left(4 b_{1} \beta-b_{3}^{2}\right)},
\end{aligned}
$$

when $a b_{1} \beta^{2}-b_{1}^{2} c \beta^{2} \sqrt{b_{1} b_{2} \alpha}-b_{1}^{2} c_{l} \beta^{2}>0, p_{c}<p_{d}$.

From Proposition 3, we could know that the centralized decision mode has a lower product pricing compared with the decentralized decision mode; when the supply chain is able to offer the same products at a lower price, consumers absolutely will not choose a more expensive supplier; therefore, it is better for new retail supply chain enterprises to adopt the centralized decision mode.

Proposition 4. The centralized decision mode has a better profit compared with the decentralized decision $\left(\pi_{c}>\pi_{d}\right)$.

Proof. From equations (5) and (10), we know that

$$
\begin{aligned}
D_{c} & =a-b_{1} p_{c}-b_{2} t_{c}+b_{3} e_{c}, \\
D_{d} & =a-b_{1} p_{d}-b_{2} t_{d}+b_{3} e_{d}, \\
D_{c}-D_{d} & =b_{1}\left(p_{d}-p_{c}\right)+b_{3}\left(v_{c}-v_{d}\right)>0, \\
\pi_{c} & =\left(p_{c}-c-d_{c}\right) D_{c}-c_{e}=\left(p_{c}-c-c_{l}-\frac{\alpha}{t_{c}}\right) D_{c}-\beta \frac{e_{c}^{2}}{2}, \\
\pi_{d} & =\pi_{s d}+\pi_{p d}+\pi_{l d} \\
& =\left(a-b_{1} p_{d}-b_{2} t_{d}+b_{3} e_{d}\right)\left(p_{d}-c-c_{l}-\frac{\alpha}{t_{d}}\right)-\beta \frac{e_{d}^{2}}{2}, \\
& =\left(p_{d}-c-c_{l}-\frac{\alpha}{t_{d}}\right) D_{d}-\beta \frac{e_{d}^{2}}{2} \\
< & \left(p_{d}-c-c_{l}-\frac{\alpha}{t_{d}}\right) D_{c}-\beta \frac{e_{d}^{2}}{2} \\
\pi_{d}^{*}-\pi_{c} & =\left(p_{d}-p_{c}\right) D_{c},
\end{aligned}
$$

when $\quad 2 b_{1} \beta \sqrt{b_{1} b_{2} \alpha}+c_{l} b_{1}^{2} \beta+b_{1}^{2} c \beta-a b_{1} \beta<0$ and $a b_{1} \beta^{2}-b_{1}^{2} c \beta^{2}-2 b_{1} \beta^{2} \sqrt{b_{1} b_{2} \alpha}-b_{1}^{2} c_{l} \beta^{2}<0, p_{c}<p_{d}$.

From Proposition 4 , we could know that the centralized decision supply chain mode has a better profit compared with the decentralized decision mode. This means that in the decentralized decision mode, the profit of the supply chain cannot reach the optimal state due to the existence of double 
marginal effect in the supply chain. Therefore, the new retail supply chain enterprises need to explore effective ways of cooperation to obtain higher profits as much as possible.

To sum up, we conclude that both decision modes have the same optimal delivery time. The service level, the market demand, and the total profit of the supply chain under the centralized decision mode are higher than those under the decentralized decision mode, while the optimal selling price is lower than the decentralized decision mode. These results mean that the supply chain has not reached the optimal state. We need to design an effective coordination contract to strengthen the tripartite cooperation that improves the service level, expands the market demand, increases the supply chain profits, and achieves the supply chain coordination.

\section{Supply Chain Coordination Contract}

Propositions 1 to 4 show that the supply chain under the centralized decision mode wins a larger market and yields to a higher profit, with lower price and higher service. However, in the centralized decision mode, the platform service providers and the logistics provider serve for product sales and they operate based on cost. The product suppliers get the profit from the whole supply chain. However, the logistics providers and the platform service providers, as independent decision makers, have no motivation to operate based on cost. In the case of limited funds, they have no encouragement to invest more resources to improve the platform service level and the distribution level. Thus, we need to design an effective coordination mechanism that shall not only make the total revenue of the decentralized decision mode equal to the centralized decision mode but also make the distribution revenue of the product suppliers, platform service providers, and logistics providers equal or better than their respective revenue without the contract. The combination contract has these conditions as follows:

(1) The platform service providers charge the service fee $m_{p p}$ to the product suppliers

(2) The logistics providers charge the distribution fee $m_{l l}$ per unit of goods to the product suppliers

(3) The product suppliers share the input cost of platform service improvement $\phi_{1}$ to the platform service providers and share the input cost of logistics improvement $\phi_{2}$ to the logistics providers

Consequently, the profit functions of the product suppliers $\left(\pi_{s}\right)$, the platform service providers $\left(\pi_{p}\right)$, and the logistic providers $\left(\pi_{l}\right)$ are as follows:

$$
\begin{aligned}
& \pi_{s}=\left(p_{1}-c-m_{l l}\right) D-m_{p p}-\phi_{1}-\phi_{2}, \\
& \pi_{p}=m_{p p}-\beta \frac{e_{1}^{2}}{2}+\phi_{1}, \\
& \pi_{l}=\left(m_{l l}-d_{1}\right) D+\phi_{2},
\end{aligned}
$$

and the market demand function $D$ is as follows:

$$
\begin{aligned}
& D=a-b_{1} p_{1}-b_{2} t_{1}+b_{3} e_{1}, \\
& d_{1}=c_{l}-\frac{\alpha}{t_{1}},
\end{aligned}
$$

where $p_{1}, e_{1}$, and $t_{1}$ are the optimal product price, platform service level, and delivery time under contract coordination, respectively, and $d_{1}$ is the unit product logistics cost. The profit of supply chain after coordination should be equal to the centralized decision mode's profit of supply chain. Also, the profit of the product suppliers, the platform service providers, and the logistics provider should be improved compared with the decentralized decision mode before coordination. That is,

$$
\begin{aligned}
\pi_{s}+\pi_{p}+\pi_{l} & =\pi_{c}, \\
\pi_{s} & >\pi_{s d}, \\
\pi_{p} & >\pi_{p d}, \\
\pi_{l} & >\pi_{l d}
\end{aligned}
$$

Bringing equations (28) and (29) into equation (27), then combining condition formulas (28) and (31), and calculating equations (25)-(27), we obtain the following:

$$
\begin{gathered}
m_{p p}=\beta \frac{e_{1}^{2}}{2}, \\
m_{l l}=d_{1}, \\
\varphi_{1}>\pi_{p d}, \\
\varphi_{2}>\pi_{l d}, \\
\varphi_{1}+\varphi_{2}<\pi_{c}-\pi_{s} .
\end{gathered}
$$

Using the calculation method to equation (26), we can obtain the expressions of $p_{1}, e_{1}$, and $t_{1}$ as follows:

$$
\begin{aligned}
& p_{1}=\frac{\left[\left(a+b_{1} c+b_{1} c_{l}\right) \beta-b_{3}^{2}\left(c+c_{l}\right)\right] \sqrt{b_{1} b_{2} \alpha}-b_{2} b_{3}^{2} \alpha}{\left(2 b_{1} \beta-b_{3}^{2}\right) \sqrt{b_{1} b_{2} \alpha}}, \\
& e_{1}=\frac{\left(a-b_{1} c-b_{1} c_{l}-2 \sqrt{b_{1} b_{2} \alpha}\right) b_{3}}{2 b_{1} \beta-b_{3}^{2}} \\
& t_{1}=\sqrt{\frac{b_{1} \alpha}{b_{2}}} .
\end{aligned}
$$

Bringing equations (25)-(27) into equations (33)-(35), we obtained the profits of product suppliers, platform service providers, and logistics provider as follows: 


$$
\begin{aligned}
\pi_{s}= & \left(p_{1}-c-c_{l}-\frac{\alpha}{t_{2}}\right)\left(a-b_{1} p_{1}-b_{2} t_{1}+b_{3} e_{1}\right) \\
& -\beta \frac{v_{1}^{2}}{2}-\phi_{1}-\phi_{2}, \\
\pi_{p}= & \phi_{1}, \\
\pi_{l}= & \phi_{2},
\end{aligned}
$$

and the total supply chain profit is as follows:

$$
\begin{gathered}
\pi=\pi_{s}+\pi_{p}+\pi_{l}=\left(p_{1}-c-\alpha-\frac{\alpha}{t_{1}}\right) \\
\left(a-b_{1} p_{1}-b_{2} t_{1}+b_{3} e_{1}\right)-\beta \frac{e_{1}^{2}}{2} .
\end{gathered}
$$

Since $p_{1}=p_{c}, v_{1}=v_{c}$, and $t_{1}=t_{c}$, we get $\pi=\pi_{c}$, that is, the profit of supply chain after coordination is equal to the profit of supply chain in the centralized decision mode and that the profits of the product suppliers, the platform service providers, and the logistics providers are all improved. In conclusion, we proved that the combination contract effectively coordinates the supply chain.

\section{Numerical Analysis}

In the analysis in Section 3, we know that compared with the decentralized decision mode, in the centralized decision mode, we can obtain lower price, higher service level, win a larger market, and obtain higher profits. At the same time, we point out that the centralized mode, as an ideal operation mode, still has some drawbacks; that is, the platform service providers and logistics providers serve for product sales and operate based on cost, and it is contrary to the profit-oriented operating principles of enterprises. In order to encourage platform service providers and logistics providers to invest more cost to improve service level and delivery time, we designed combination contract in Section 4 to coordinate the supply chain. Under the coordinated supply chain decision mode, the total profit of the supply chain remains unchanged, while the profits of the platform service providers and logistics providers increase, which perfectly solves the shortcomings of the centralized decision mode. From equations (9) and (33)-(35), we know that the product price, service level, and delivery time of the coordinated supply chain decision mode are same as those under the centralized decision mode. Therefore, in order to show the difference of the optimal decision results under the centralized and decentralized decision mode and the effectiveness of the combination contract, we numerically analyze the decentralized decision mode and combination contract. In the new retail supply chain mode, the platform provider is one of the most important members as online market. In order to analyze the function of the platform service providers in the operation of the supply chain, we discuss the impact of the change of service level sensitivity coefficient $b_{3}$ on the service level, product pricing, and the supply chain profit.
6.1. Numerical Analysis of the Combination Contract. To verify that the combination contract has an incentive effect on reducing the product price, improving the service level, shortening the delivery time, and increasing the supply chain profit compared with the decentralized decision mode, we compared the coordinated decision mode and the decentralized decision mode supply chain by numerical analysis. We referred the literature $[22,37]$ in assigning the values of the related parameters, setting the market basic demand parameter $a=50$, the product $\operatorname{cost} c=10$, the price sensitivity coefficient of demand $b_{1}=2$, the service level sensitivity coefficient of demand $b_{3}=1$, the inherent logistics cost $c_{l}=1$, the sensitivity coefficient of logistics cost to delivery time $\alpha=2$, and the platform service cost coefficient $\beta=1$. We assign these parameters in Table 2. By assuming the value of sensitivity coefficient $b_{2}$ as an independent variable, we set $b_{2} \in[0.1,4]$ and compare the optimal price, the optimal service level, the optimal delivery time, and the supply chain profit with the change of $b_{2}$ under the coordinated mode and the decentralized decision mode supply chain.

From Figures 2 and 3, we can conclude the following.

6.1.1. The Combination Contract Reduces the Product Price. According to Figure 2, the product price after supply chain coordination is lower than the decentralized decision mode. With the increase in $b_{2}$, the two price curves gradually overlap because, to a certain range, the effective management of the supply chain shall lower the product prices, but the product prices cannot be infinitely reduced and the prices are ultimately determined by the value of the product itself. Moreover, the product price curve of the coordinated supply chain is relatively flat with a small fluctuation range that indicates the combination contract controls the product price effectively. When the consumers are sensitive to the product price, lower product price leads to a higher number of customers, and consequently a larger market for the supply chain. Thus, each member of the supply chain should strengthen the cooperation to reduce the product price and win a larger market.

6.1.2. The Combination Contract Improves the Platform Service Level. According to Figure 2, the service level of the platform after supply chain coordination is higher than the decentralized decision mode. Under the coordination of the combination contract, the product suppliers share the input cost of the platform service; as a result, the platform service providers have more resources to invest in the improvement of the service level. Higher service level shall lead to higher product satisfaction, leading to a favorable condition for the sales of the product suppliers, which is win-win cooperation.

6.1.3. The Combination Contract Shortens the Delivery Time. According to Figure 3, when the customers are sensitive to the delivery time, the delivery time becomes shorter. The optimal delivery time curve is equivalent, indicating that the optimal delivery time is equal for both decision modes because the optimal delivery time is determined by the level 
TABLE 2: Value of parameters.

\begin{tabular}{lccccccc}
\hline Parameter & $a$ & $c$ & $b_{1}$ & $b_{3}$ & $c_{l}$ & $\alpha$ & $\beta$ \\
\hline Shark bay & 50 & 10 & 2 & 1 & 1 & 2 & 1 \\
\hline
\end{tabular}

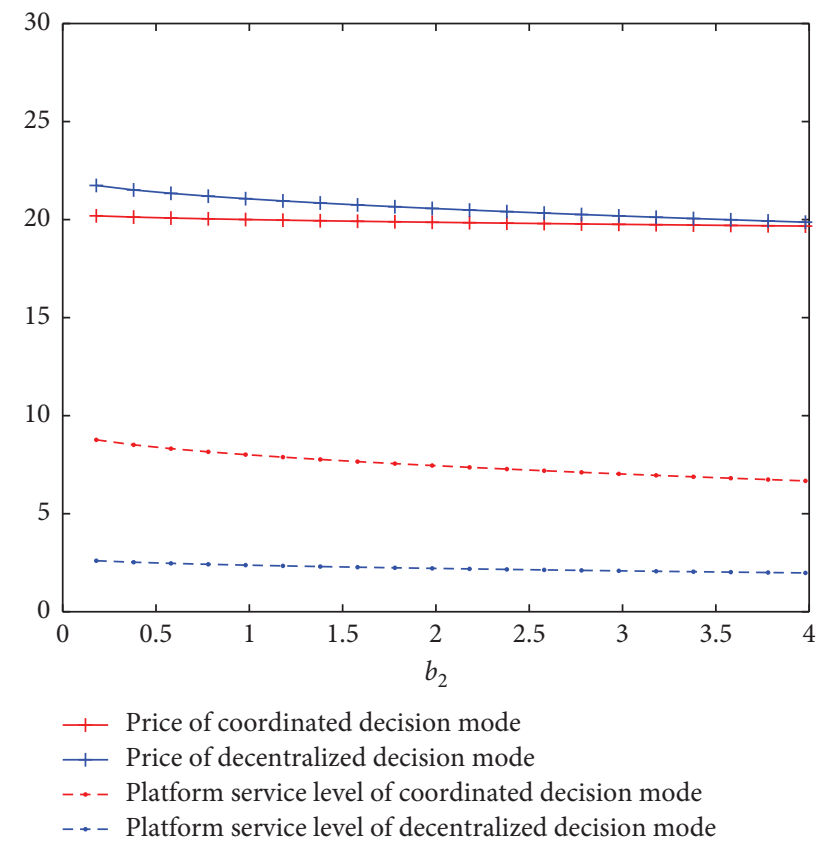

FIGURE 2: The price and platform service level of the coordinated mode and decentralized mode supply chain.

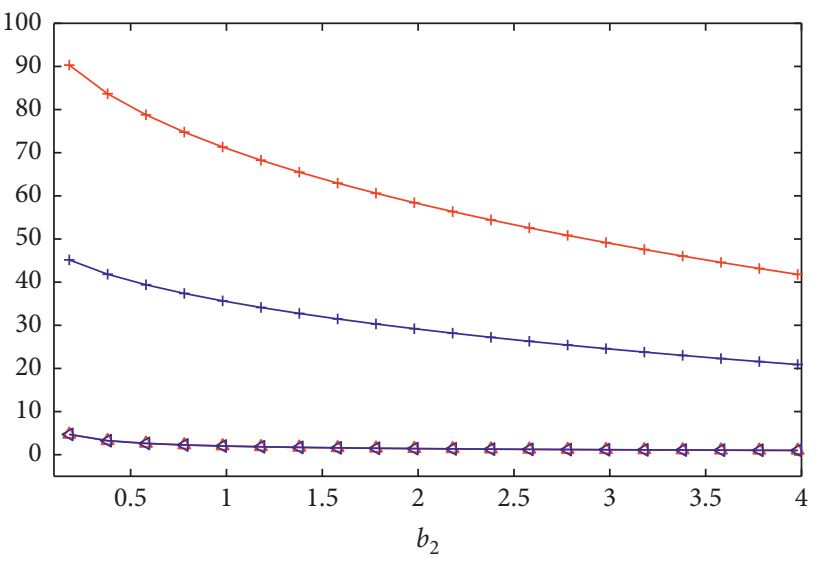

$\triangle$ Delivery time of coordinated decision mode

$\neg$ Delivery time of decentralized decision mode

+ Profit of coordinated decision mode

$\rightarrow$ Profit of decentralized decision mode

Figure 3: The delivery time and supply chain profit of the coordinated mode and decentralized mode supply chain.

of social productivity and logistics cost, and it is not affected by the members of the supply chain. However, shortening the delivery time helps the supply chain to occupy more market, which shall increase the investment in logistics construction that leads to shorter delivery time and win more consumers. Some online platforms (e.g., JD.com and Suning.com) choose to invest heavily in building their own logistics system, while others (e.g., Alibaba) choose thirdparty logistics and invest a lot to cooperate logistic providers (e.g., Cainiao Technology Company) to shorten the delivery time. No matter what kind of logistics mode the platform service providers choose, they are looking for effective ways to shorten the delivery time.

6.1.4. The Combination Contract Improves Supply Chain Profit. According to Figure 3, the total profit of the coordinated supply chain is higher than the decentralized decision mode. The cooperation integrates the resources of the members of the supply chain, thus improving the efficiency and service level, occupying a larger market at a lower price, and obtaining more profits. However, when consumers demand higher requirements for the delivery time, the supply chain has to invest more resources to improve the logistics level. This investment is very costly and will grow exponentially with the shortening time of delivery since the logistics cost function is the exponential function of delivery time. The high investment in logistics shall reduce the total profit of the supply chain. Thus, with the increase in $b_{2}$, the profit curve of the supply chain decreases.

\subsection{Numerical Analysis of Service Level Sensitivity Coefficient} $b_{3}$. The platform service providers play an important role in the new retail supply chain. In Section 6.1, we used the delivery time sensitivity coefficient $b_{2}$ as the independent variable to analyze the effectiveness of the combination contract, and we also analyzed the impact of delivery time on supply chain operation. Therefore, we select $b_{3}$ as the research object to discuss the impact of service level on supply chain operation. We analyze the influence of the service level sensitivity coefficient $b_{3}$ on platform service level, product price, and platform profit to explore the role of the platform. We use the same parameter assignment as shown in Table 2, and we assume that $b_{2}=2$.

6.2.1. Influence of Service Level Sensitivity Coefficient on the Platform Service Level. According to Figure 4, as the service level sensitivity coefficient increases, the platform service level also increases. The platform service level on the coordination mode is higher than that of the decentralized decision mode, indicating that the coordination supply chain's combination contract proposed in this paper improves the platform service level. Furthermore, the platform service level curve becomes saturated with the increase in service level sensitivity coefficient $b_{3}$, indicating that the growth of platform service level gradually slows down. The consumers' requirements for service $l$ can stimulate the platform to improve the service level; however, the service level is restricted by the network facilities, marketing ability, and other factors.

6.2.2. Influence of Service Level Sensitivity Coefficient on the Product Price. According to Figure 5, the product price increases along with the increase in the service level sensitivity 


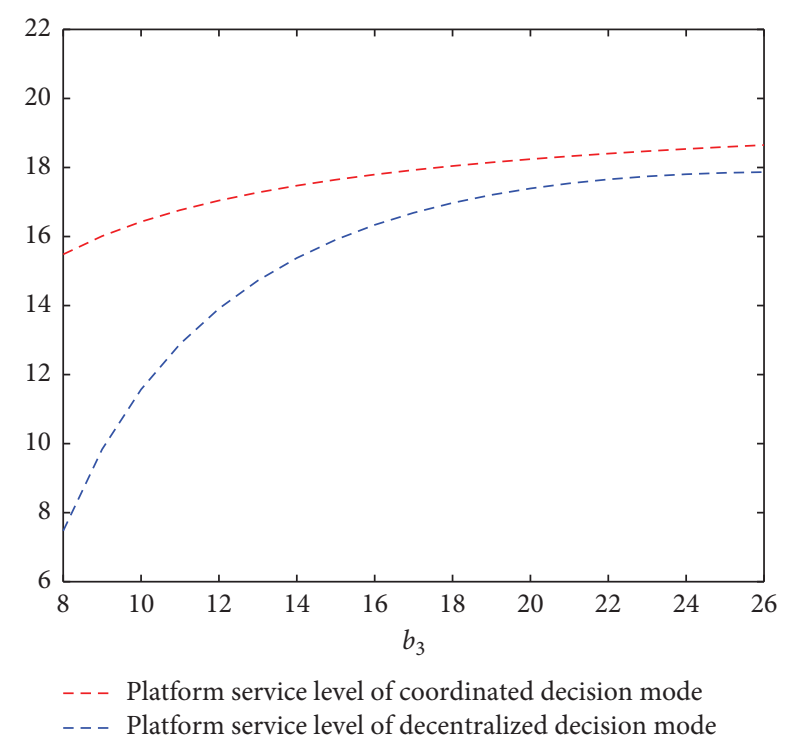

FIGURE 4: Influence of $b_{3}$ on the platform service level.

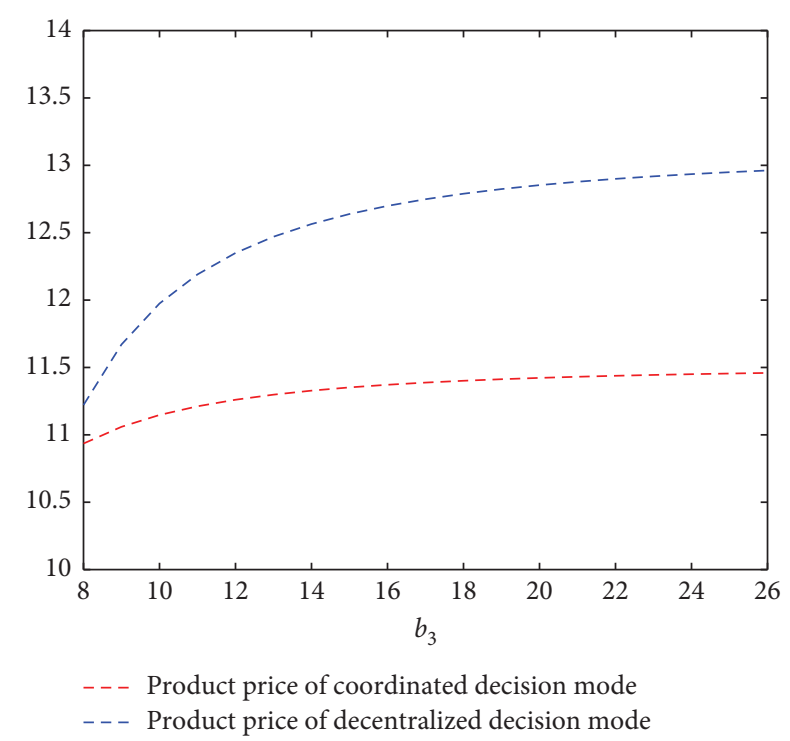

FIGURE 5: Influence of $b_{3}$ on the product price.

coefficient, showing that, given a higher service level, the businesses may increase the product price appropriately.

The product price of the coordination mode is lower than that of the decentralized mode and the curve saturated, indicating that the coordination contract proposed in this paper effectively controls the product price. When the customers' sensitivity to the service level increases, the product price does not drastically change because the product price is not only affected by the service level and customers' consumption psychology but also by the product cost and the market condition.

6.2.3. Influence of Service Level Sensitivity Coefficient on the Platform Profit. According to equation (A.5), the profit of the platform service provider is a constant on the

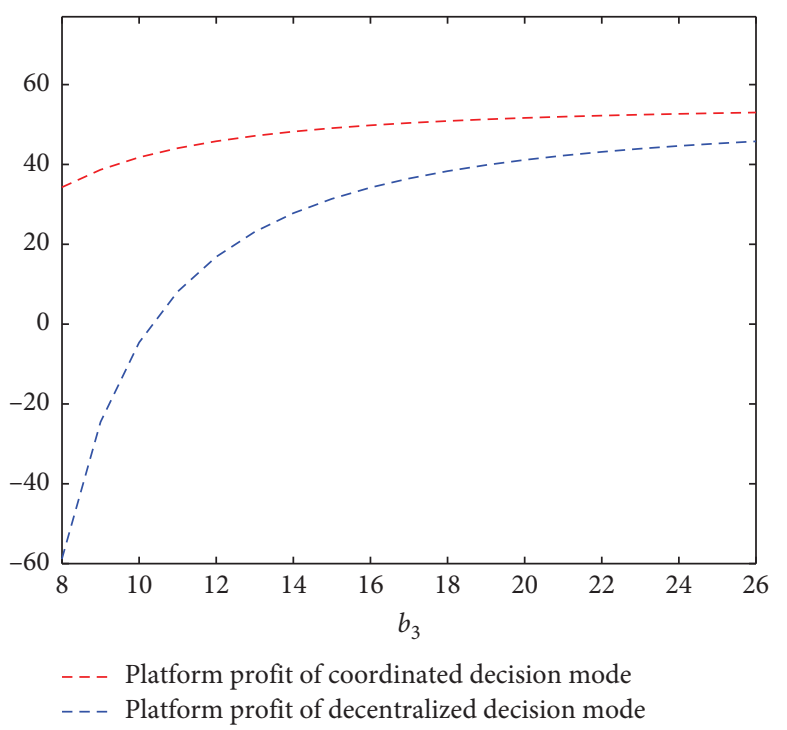

FIGURE 6: Influence of $b_{3}$ on the profit of platform service provider.

coordination mode and this profit is paid by the product suppliers. When the product suppliers obtain a larger profit, the profit of the platform service provider shall increase accordingly. Therefore, we discuss the impact of $b_{3}$ on the product suppliers' profit on the coordination mode, to infer the change of the platform service providers' profit. In Figure 6, in both modes, the platform service providers' profit increases along with the service level sensitivity coefficient, showing that when consumers have higher requirements for service, the improvement of service level shall bring higher profit to the product suppliers (and the platform) and then to the platform service providers. Since the profit of the logistics providers is also a constant value paid by the product suppliers, we can infer that the increase in the product suppliers' profit from shorter delivery time shall also increase the profit of the logistics providers. These results indicate that the higher requirements from consumers for service and delivery time shall encourage the cooperation between the product suppliers, the platform service providers, and the logistics providers, as well as promote the capital investment of the three members to improve the service level and distribution level.

\section{Conclusion and Future Research}

In this paper, we studied the new retail supply chain with product suppliers, platform service providers, and logistics providers. The service level of the platform service providers and the distribution level of the logistics providers affect the consumers' demand. We want set up effective coordination methods to make the product suppliers optimize the product price, the platform service providers improve the platform service level, and the logistics providers improve the distribution service level.

We presented the optimal decision expression of the product suppliers, platform service providers, and logistics providers on both centralized and decentralized decision modes. We calculated the optimal product price, service 
level, and delivery time, and we found that the centralized decision mode can obtain lower price, higher service level, and lower delivery time. We also showed that the market demand and the total profit of the supply chain on the centralized decision mode are higher than those on the decentralized decision mode. Then, we point out the drawbacks of the centralized decision mode, and we designed a coordination contract to strengthen the tripartite cooperation to improve the service level, expand the market demand, and increase the supply chain profits.

We performed a numerical analysis to prove the feasibility and the effectiveness of the coordination contract strategies. We discovered that the increase in service level sensitivity coefficient and the delivery time sensitivity coefficient improves the platform service providers' service level and the logistics providers' distribution effort level. The combination contract proposed in this paper effectively encourages the platform service providers to improve the service level and the logistics providers to shorten the delivery time. With the improvement of service level and the shortening of delivery time, the demand shall increase, leading the three parties to cooperate more, in other words, promoting the integration of the online, offline, and logistics of the new retail supply chain.

In this paper, we assumed that the platform service providers' service level and the logistics providers' distribution level are unrestricted while establishing the consumer demand function. However, in reality, the platform service providers' service level is affected by many factors, such as the current technological condition and enterprise marketing capability, and cannot be unlimitedly improved. Likewise, the logistics providers' delivery time cannot be arbitrarily shortened. Therefore, in future research, we are going to consider the optimal decision problem of the supply chain with limited platform service providers' service level and the logistics providers' distribution level.

\section{Appendix}

\section{Proof of Theorem 1}

First, solve the first partial derivatives of $\pi_{c}$ under $p_{c}, e_{c}$, and $t_{c}$ of equation (8), as follows:

$$
\left\{\begin{array}{l}
\frac{\partial \pi_{c}}{\partial p_{c}}=a-b_{1} p_{c}-b_{2} t_{c}+b_{3} e_{c}-\left(p_{c}-c-c_{l}-\frac{\alpha}{t_{c}}\right) b_{1}, \\
\frac{\partial \pi_{c}}{\partial e_{c}}=\left(p_{c}-c-c_{l}-\frac{\alpha}{t_{c}}\right) b_{3}-\beta e_{c}, \\
\frac{\partial \pi_{c}}{\partial t_{c}}=\frac{\alpha\left(a-b_{1} p_{c}-b_{2} t_{c}+b_{3} e_{c}\right)}{t_{c}^{2}}-\left(p_{c}-c-c_{l}-\frac{\alpha}{t_{c}}\right) b_{2} .
\end{array}\right.
$$

The second-order partial derivatives of $\pi_{c}$ under $p_{c}, e_{c}$, and $t_{c}$ are presented as follows:

$$
\left\{\begin{array}{l}
\frac{\partial^{2} \pi_{c}}{\partial p_{c}^{2}}=-2 b_{1}<0, \\
\frac{\partial^{2} \pi_{c}}{\partial e_{c}^{2}}=-2 \beta<0, \\
\frac{\partial^{2} \pi_{c}}{\partial t_{c}^{2}}=-\frac{\alpha\left(a-b_{1} p_{c}+b_{3} e_{c}\right)}{t_{c}^{3}}<0 .
\end{array}\right.
$$

From equations (A.1) and (A.2), we know that the profit function of the supply chain is a concave function of the product price $p_{c}$, service level $e_{\mathcal{c}}$ and delivery time $t_{c}$ thus, with optimal product price $p_{d}$, service level $e_{c}$, and delivery time $t_{c}$, we can maximize the profit of the product supplier. Let

$$
\left\{\begin{array}{l}
\frac{\partial \pi_{c}}{\partial p_{c}}=0 \\
\frac{\partial \pi_{c}}{\partial e_{c}}=0 \\
\frac{\partial \pi_{c}}{\partial t_{c}}=0
\end{array}\right.
$$

By solving equation (A.3), we can get

$$
\left\{\begin{array}{l}
p_{c}=\frac{\left(a-b_{2} t_{c}+b_{3} e_{c}\right)+b_{1}\left(c+c_{l}+\alpha / t_{c}\right),}{2 b_{1}} \\
e_{c}=\frac{\left(a-b_{1} c-b_{1} c_{l}-2 \sqrt{b_{1} b_{2} \alpha}\right) b_{3}}{2 b_{1} \beta-b_{3}^{2}}, \\
t_{c}=\sqrt{\frac{b_{1} \alpha}{b_{2}}} .
\end{array}\right.
$$

Substitute the expression of $t_{c}$ and $e_{c}$, into $p_{c}$ and obtain the optimal pricing $p_{c}$ as follows:

$$
p_{c}=\frac{\infty\left[\left(a+b_{\partial 1} c+b_{1} c_{l}\right) \beta-b_{3}^{2}\left(c+c_{l}\right)\right] \sqrt{b_{1} b_{2} \alpha}-b_{2} b_{3}^{2} \alpha}{\left(2 b_{1} \beta-b_{3}^{2}\right) \sqrt{b_{1} b_{2} \alpha}} .
$$

\section{B. Proof of Equation $\boldsymbol{e}_{\boldsymbol{d}}$}

By solving the first partial derivative and the second partial derivative of $e_{d}$, we obtained the following:

$$
\begin{aligned}
& \frac{\partial \pi_{p d}}{\partial e_{d}}=\frac{b_{3} m_{p}}{2}-\beta e_{d}, \\
& \frac{\partial^{2} \pi_{p d}}{\partial e_{d}^{2}}=-\beta<0 .
\end{aligned}
$$


From equation (A.7), we know that the profit function of the platform service providers is a concave function of the platform service level $e_{d}$; thus, with optimal platform service level $e_{d}$, we can maximize the profit of the platform service provider. Let

$$
\frac{\partial \pi_{p d}}{\partial v_{e}}=0 .
$$

Obtain the optimal platform service level as follows:

$$
e_{d}=\frac{b_{3} m_{p}}{2 \beta} \text {. }
$$

\section{Data Availability}

The data used to support the findings of the study are included within the article.

\section{Conflicts of Interest}

The authors declare that they have no conflicts of interest regarding the publication of the paper.

\section{Acknowledgments}

This research was supported by the National Natural Science Foundation of China (no. 71801004), Key Project of Natural Science Foundation of Anhui Universities (no. KJ2020A0237), and Philosophy and Social Science Planning Project of Anhui Province (no. AHSKQ2020D15).

\section{References}

[1] L. Qi, Q. Wang, and P. Song, "The effects of agency selling on reselling on hybrid retail platforms," International Journal of Electronic Commerce, vol. 23, no. 4, pp. 524-556, 2019.

[2] S. Han, Y. Fu, B. Cao, and Z. Luo, "Pricing and bargaining strategy of e-retail under hybrid operational patterns," Annals of Operations Research, vol. 270, no. 1-2, pp. 179-200, 2018.

[3] M. Gümüş, S. Li, W. Oh, and S. Ray, "Shipping fees or shipping free? A tale of two price partitioning strategies in online retailing," Production and Operations Management, vol. 22, no. 4, pp. 758-776, 2013.

[4] K.-W. Wu, S. Y. Huang, D. C. Yen, and I. Popova, "The effect of online privacy policy on consumer privacy concern and trust," Computers in Human Behavior, vol. 28, no. 3, pp. 889-897, 2012.

[5] F. Morath and J. Münster, "Online shopping and platform design with ex ante registration requirements," Management Science, vol. 64, no. 1, pp. 360-380, 2017.

[6] T. Zhang, G. Li, K. K. Lai, and J. W. K. Leung, "Information disclosure strategies for the intermediary and competitive sellers," European Journal of Operational Research, vol. 271, no. 3, pp. 1156-1173, 2018.

[7] M. Tang and Z. Wu, "Research on the mechanism of big data on consumer behaviour using the models of $\mathrm{C} 2 \mathrm{C} \mathrm{e}$-commerce and countermeasures," African Journal of Business Management, vol. 9, no. 1, pp. 18-34, 2015.

[8] I. Manuela and R. Ulewicz, "Evaluation of quality of the e-commerce service," International Journal of Ambient Computing and Intelligence, vol. 9, no. 2, pp. 55-66, 2018.
[9] P. Zhang, Y. He, and X. Zhao, "“Preorder-online, pickupin-store" strategy for a dual-channel retailer," Transportation Research Part E: Logistics and Transportation Review, vol. 122, pp. 27-47, 2019.

[10] P. Zhang, Y. He, and C. Shi, "Retailer's channel structure choice: online channel, offline channel, or dual channels?," International Journal of Production Economics, vol. 191, pp. 37-50, 2017.

[11] M. K. Al-nawayseh, M. M. Alnabhan, M. M. Al-Debei, and W. Balachandran, "An adaptive decision support system for last mile logistics in e-commerce," International Journal of Decision Support System Technology, vol. 5, no. 1, pp. 40-65, 2013.

[12] M. Koptak, M. Džubáková, V. Vasilienè-Vasiliauskienè, and A. V. Vasiliauskas, "Work standards in selected third party logistics operations: MTM-LOGISTICS case study," Procedia Engineering, vol. 187, pp. 160-166, 2017.

[13] X. Qin, Z. Liu, and L. Tian, "The strategic analysis of logistics service sharing in an e-commerce platform," OmegaInternational Journal of Management Science, vol. 92, Article ID 102153, 2019.

[14] C. Zhao and H. Hu, "Urban end distribution optimization under e-commerce environment," Journal of Shanghai Jiaotong University (Science), vol. 21, no. 5, pp. 513-523, 2016.

[15] H. Peng, Y. He, and H. Xu, "Buy-online-and-deliver-fromstore strategy for a dual-channel supply chain considering retailer's location advantage," Transportation Research Part E: Logistics and Transportation Review, vol. 144, pp. 102-127, 2020.

[16] M. Murfield, C. A. Boone, P. Rutner, and R. Thomas, "Investigating logistics service quality in omni-channel retailing," International Journal of Physical Distribution \& Logistics Management, vol. 47, no. 4, pp. 263-296, 2017.

[17] M. Lin, C. Jin, and Y. Huo, "Selection of logistics service modes in e-commerce based on multi-oligopolies cournot competition," International Journal of Shipping and Transport Logistics, vol. 11, no. 4, p. 354, 2019.

[18] H. Qian, "E-commerce logistics mode selection based on network construction," Modern Economy, vol. 10, no. 1, pp. 198-208, 2019.

[19] S. Mandal, S. Bhattacharya, V. R. Korasiga, and R. Sarathy, "The dominant influence of logistics capabilities on integration," International Journal of Disaster Resilience in The Built Environment, vol. 8, no. 4, pp. 357-374, 2017.

[20] E. Uzel and O. Tuna, "The effect of logistics service quality on past purchase behavioral intention in on-line shopping," Journal of Management Marketing and Logistics, vol. 1, no. 3, pp. 241-258, 2014.

[21] X. Huang, S.-M. Choi, W.-K. Ching, T.-K. Siu, and M. Huang, "On supply chain coordination for false failure returns: a quantity discount contract approach," International Journal of Production Economics, vol. 133, no. 2, pp. 634-644, 2011.

[22] L. Zhao, L. Li, S. Yao, C. Li, and Y. Wu, "Research on pricing and coordination strategy of a sustainable green supply chain with a capital-constrained retailer," Complexity, vol. 2018, Article ID 6845970, 12 pages, 2018.

[23] Z. Zhang, P. Wang, M. Wan, J. Guo, and J. Liu, "Supply chain decisions and coordination under the combined effect of overconfidence and fairness concern," Complexity, vol. 2020, Article ID 3056305, 16 pages, 2020.

[24] O. C. Demirag, O. Baysar, P. Keskinocak, and J. L. Swann, "The effects of customer rebates and retailer incentives on a manufacturer's profits and sales," Naval Research Logistics, vol. 57, no. 1, pp. 88-108, 2019. 
[25] L. Chang Hwan, B.-D. Rhee, and T. C. E. Cheng, "Quality uncertainty and quality-compensation contract for supply chain coordination," European Journal of Operational Research, vol. 228, no. 3, pp. 582-591, 2013.

[26] P. He, Y. He, C. Shi, H. Xu, and L. Zhou, "Cost-sharing contract design in a low-carbon service supply chain," Computers \& Industrial Engineering, vol. 139, pp. 106-160, 2020.

[27] Y. He and X. Zhao, "Coordination in multi-echelon supply chain under supply and demand uncertainty," International Journal of Production Economics, vol. 139, no. 1, pp. 106-115, 2012.

[28] Y. He, X. Zhao, L. Zhao, and J. He, "Coordinating a supply chain with effort and price dependent stochastic demand," Applied Mathematical Modelling, vol. 33, no. 6, pp. 27772790, 2009.

[29] Y. Po-Chung, H.-M. Wee, S.-L. Chung et al., "Pricing and replenishment strategy for a multi-market deteriorating product with time-varying and price-sensitive demand," Journal of Industrial and Management Optimization, vol. 9, no. 4, pp. 769-787, 2013.

[30] P. Afèche and J. M. Pavlin, "Optimal price-lead time menus for queues with customer choice: priorities, pooling \& strategic delay," Management Science, vol. 62, no. 1, pp. 24122436, 2013.

[31] T. Zhang and J. Xu, "Pricing and logistics service level decisions in retailer's dual-channel cooperation," The Open Cybernetics \& Systemics Journal, vol. 9, no. 1, pp. 851-856, 2015.

[32] G. Li, X. Guan, M.-q. Liu, and M.-y. Shan, "Two-echelon inventory model with service level constraint and controllable lead time sensitive to order quantity," Journal of Central South University, vol. 20, no. 11, pp. 3324-3333, 2013.

[33] Y. He, H. Huang, and D. Li, "Inventory and pricing decisions for a dual-channel supply chain with deteriorating products," Operational Research, vol. 20, no. 3, pp. 1461-1503, 2020.

[34] J. Ma, F. Zhang, and B. Bao, "Dynamic game and coordination strategy of multichannel supply chain based on brand competition," Complexity, vol. 2019, Article ID 4802360, 26 pages, 2019.

[35] H. Peng, Y. He, and H. Xu, "Channel structure and pricing in a dual-channel closed-loop supply chain with government subsidy," International Journal of Production Economics, vol. 213, pp. 108-123, 2019.

[36] Y. Zhong, F. Guo, Z. Wang et al., "Coordination analysis of revenue sharing in e-commerce logistics service supply chain with cooperative distribution," SAGE Open, vol. 9, no. 3, pp. 1-15, 2019.

[37] S. S. Sana, "Optimal contract strategies for two stage supply chain," Economic Modelling, vol. 30, pp. 253-260, 2013.

[38] K. C. So and J.-S. Song, "Price, delivery time guarantees and capacity selection," European Journal of Operational Research, vol. 111, no. 1, pp. 28-49, 1998.

[39] P. Hanchuan, W. Ruifang, D. Hao, and Z. Feng, "The research of logistics cost and influencing factors based on cross docking," Procedia-Social and Behavioral Sciences, vol. 96, pp. 1812-1817, 2013.

[40] X. Zhou, F. Ma, and X. Chen, "An information sharing model in dual-channel supply chain in E-commerce environment," International Journal on Advances in Information Sciences and Service Sciences, vol. 3, no. 7, pp. 232-243, 2011. 